\title{
Effect of heat stress on age at first calving in Mehsana buffaloes under field progeny testing programme
}

\author{
PB Purohit ${ }^{1,2}$, Jay Prakash Gupta ${ }^{1}$, JD Chaudhari $^{1}$, TM Bhatt $^{1}$, MM Pawar $^{1}$, AK Srivastava $^{1}$, MP Patel $^{1}$, PA Patel $^{3}$ and MN \\ Prajapati $^{3}$
}

Received: 27 March 2021 / Accepted: 20 July 2021 / Published online: 07 September 2021

(c) Indian Dairy Association (India) 2021

\begin{abstract}
The records of 7791 Mehsana buffaloes sired by 182 sires on age at first calving (AFC) spread over a period of 24 years (1989 to 2012), collected from Dudhsagar Research and Development Association (DURDA), Dudhsagar Dairy, Mehsana. Meteorological data of the region (where field progeny testing was undergoing), were collected from the center of Indian Meteorological Department (IMD), Pune to know the association of AFC with heat stress indicators. The least squares mean and heritability of AFC were estimated. Various heat stress models were screened for optimization (Based on value of $\mathrm{R}^{2}$, adjusted $\mathrm{R}^{2}$, AIC and BIC) and effect of heat stress was quantified. Depending on the estimate of AFC and THI, months of the year were classified in to various heat stress zones. Sires were evaluated (both by BLUP-SM and BLUP-AM) for AFC in different $\mathrm{HSZ}$, in order to identify optimum sire for each of the zone. The least squares mean estimate for $\mathrm{AFC}$ was $1419.61 \pm 2.18$ days. The heritability estimates were obtained as $0.14 \pm 0.02$ (LSML), $0.775 \pm 0.003$ (BLUP-SM) and $0.13 \pm 0.023$ (BLUP-AM). THI 6 model (Yousef, 1985) was found to be the best suited model and it was observed that $\mathrm{AFC}$ was declined by 1.26 day with per unit rise in THI. Year was classified in to NHSZ (non heat stress zone November to March), HSZ (heat stress zone- April to October) and CHSZ (critical heat stress zone- June to August). The average breeding values of Mehsana buffalo bulls evaluated for AFC by BLUP-SM and BLUP-AM in NHSZ, HSZ and in CHSZ were estimated to be $1389.36,1380.37$ and 1375.04 days and 1389.33,
\end{abstract}

${ }^{1}$ Kamdhenu University, Sardarkrushinagar, Gujarat, ${ }^{2}$ ICAR-NDRI, Karnal, ${ }^{3}$ DURDA, Mehsana, Gujarat, India

Jay Prakash Gupta $(\bowtie)$

College of Veterinary Science and Animal Husbandry,

Kamdhenu University, Gujarat-385 506, India

Email:jp0prakash01@gmail.com
1382.85 and 1375.53 days, respectively. It was indicated that the bulls having superior performance in NHSZ were not as better performer in HSZ and CHSZ. This warrants that evaluation of bulls may be done separately in each heat stress zone and suitable bull for breeding under each HSZ may be identified.

Keywords: Age at first calving, BLUP, Heat stress, Progeny testing, Sire evaluation

\section{Introduction}

India is leading milk producer in the world, having annual production to the tune of 187.75 million tonnes. Out of total milk produced in the country, about $49 \%$ is contributed by buffaloes, 35 per cent of which is by the well defined 17 breeds of buffaloes (BAHS, 2019). Gujarat is rich in indigenous buffalo germplasm with four buffalo breeds viz. Banni, Jaffrabadi, Mehsana and Surti. Among these, Mehsana is one of the important breeds with 3.6 million populations and ranked $3^{\text {rd }}$ in the country. Mehsana buffaloes have natural habitat within areas of North Gujarat which is having a great influence on development of dairy sector in Gujarat (Anonymous, 2013). In the recent past, the livestock sector has improved a lot but the pace of improvement is not as needed. It is expected that in near future with an increase in human population, the demand for animal products will increase simultaneously. Since last few decades breeding policies are mainly focused on the production parameters which lead to decline in the fertility of animal. Age at first calving (AFC) is the period between the date of birth and date of first calving. It greatly affects the economics of dairy husbandry, as lower AFC leads to shorter generation interval and hence increases genetic gain. It is an important economic trait that directly influences the initiation of productive age which leads to lengthening of the productive period of animal, increases the productive performance of an animal, due to this cost of rearing an animal would decrease (Ojango and Pollott, 2001). In recent past due to effect of global warming, heat stress has taken greater toll on livestock production and reproduction (Purohit et al. 2020). Temperature-humidity index (THI) depicts the level of heat stress due to combining effect of ambient temperature and relative humidity and it correlate productivity with animal 
discomfort. The THI has been calculated by many workers which vary in different regions of the world due to the variation in the environmental parameters. The suitable THI model using temporal data on meteorological information in Mehsana buffaloes is due. Further, effects of THI on Age at First Calving, classification of non-heat stress, heat stress and critical heat stress zones concerning the Age at First Calving in Mehsana buffaloes has not been undertaken. Moreover, an attempt has not been so far made for genetic evaluation of bulls for Age at First Calving in relation to heat stress in sub-tropical arid climate of North Gujarat region. Taking into consideration of all the above facts, the present study was envisaged for identification of the most suitable heat stress model for AFC, quantification of effect of heat stress on $\mathrm{AFC}$, classification of heat stress zones and ultimately evaluation of Mehsana buffalo bulls for AFC in different heat stress zones.

\section{Materials and Methods}

The present study was carried out by using data on age at first calving records of 8222 buffaloes sired by 200 bulls, collected from the Dudhsagar Research and Development Association (DURDA), Dudhsagar Dairy, Mehsana for the period from 1989 to 2012. Meteorological data of research area for the same period was collected from the nearest station of Indian Meteorological Department (IMD), Pune (Maharastra). After initial screening of data, animals with abnormal records as well as sires having records of less than 10 daughters were excluded from the study. Finally, 7791 age at first calving records of Mehsna buffaloes sired by 182 sires, which distributed in 149 villages of 14 different talukas were considered.

The data were further classified and coded as per cluster and period of birth. The whole study area was classified into three different clusters, $\mathrm{C}_{1}$ as Northern part $\left(>23.30^{\circ} \mathrm{N}\right), \mathrm{C}_{2}$ as middle part $\left(23.15^{\circ} \mathrm{N}\right.$ to $\left.23.30^{\circ} \mathrm{N}\right)$ and $\mathrm{C}_{3}$ as Southern part $\left(<23.15^{\circ} \mathrm{N}\right)$. $\mathrm{C}_{1}$ includes eight Talukas viz. Harij, Kheralu, Patan, Sarswati, Satalasana, Siddhpur, Unjha and Vadnagar with 1306 records. $C_{2}$ includes three Talukas viz. Mehsana, Vijapur and Visnagar with 4394 records while $\mathrm{C}_{3}$ includes three Talukas viz. Kadi, Kalol and Mansa with 2091 records. Considering the contiguous years to have more or less similar effect, the entire data was grouped into the following six periods according to the year of birth viz, $\mathrm{P}_{1}$ (1989 to 1992), $\mathrm{P}_{2}$ (1993-1996), $\mathrm{P}_{3}$ (1997-2000), $\mathrm{P}_{4}$ (2001-2004), $\mathrm{P}_{5}$ (2005-2008), and $\mathrm{P}_{6}(2009-2012)$,

\section{Statistical analysis}

The least squares analysis of variance for unequal sub-class numbers was used for analyzing the data on AFC using the statistical model as suggested by (Harvey, 1990). The difference of means between any two subclasses of cluster and period of birth were tested for significance using Duncan's Multiple Range Test (DMRT) as modified by Kramer (1957). Heritability was estimated by paternal half-sib correlation method as per Becker
(1975) and standard error was estimated as given by Swiger et al. (1964). Further, monthly averages of AFC over twenty-four years were estimated separately based on month of birth.

\section{Estimation of Temperature Humidity Index}

The monthly average (January to December) THIs (Table 2) were calculated utilizing different models (Table 1) with the help of meteorological information (The daily average of these parameters were calculated by taking the average of the morning and evening values.) viz., monthly average Dry bulb temperature $\left(\mathrm{T}_{\mathrm{db}}\right)$, Wet bulb temperature $\left(\mathrm{T}_{\mathrm{wb}}\right)$, Dew point temperature $\left(\mathrm{T}_{\mathrm{dp}}\right)$ and Relative humidity $(\mathrm{RH})$ for the study period.

\section{Identification of optimum heat stress model and effect of heat stress on AFC in Mehsana Buffaloes}

All the buffaloes that calved during the 24 year period, were classified into different months as per their month of birth. The month-wise averages of AFC were then plotted against average THI values for all the nine models. The variations in the monthly averages of AFC were observed and linear regression analysis was performed to quantify the effect of heat stress on AFC in Mehsana buffaloes. Monthly averages of AFC of each year, scattered over twenty-four-year period were plotted against monthly average THI values. The simple linear regression analysis of AFC with THI was done with the help of the model as suggested by Draper and Smith (1998) using ' $R$ ' software ( $R$ Core Team, 2019). $\mathbf{Y}_{\mathrm{ij}}=\mathbf{a}+\mathbf{b} \mathbf{x}_{\mathrm{i}}+\mathbf{e}_{\mathrm{ij}}$ Where, $\mathrm{Y}_{\mathrm{ij}}$ is Age at first calving, $a$ is intercept, $b$ is Regression coefficient, $x_{i}$ is the monthly average THI values and $\mathrm{e}_{\mathrm{ij}}$ is random residual, $\operatorname{NID}\left(0, \sigma^{2} \mathrm{e}\right)$. The accuracy and changes in traits of heat stress models were judged by the coefficient of determination $\left(\mathrm{R}^{2}\right)$, adjusted $\mathrm{R}^{2}$, Akaike Information Criterion (AIC) and Bayesian Information Criterion (BIC) value and best-fitted models were identified. All the nine heat stress models (THI model 1-9) were compared based on regression coefficient i.e. changes (increase/ decrease) in the $\mathrm{AFC}$ for per unit change in THI values.

\section{Genetic evaluation of Mehsana bulls vis-à-vis heat stress}

To ascertain the effect of heat stress on the performance of breeding bulls, Mehsana buffalo bulls under each zone (NHSZ, HSZ and CHSZ) were evaluated separately for AFC. The bulls, under evaluation, were classified into NHSZ, HSZ and CHSZ based on the month of birth of their progeny. Sire evaluation under each zone was done only for those sires which are having five or more progenies in all the zones separately. The breeding value of sires was estimated by best linear unbiased prediction (BLUP) method as given by Henderson (1975).

In BLUP sire model (BLUP-SM), where (co)variance components were estimated by best linear unbiased prediction animal model (BLUP) using WOMBAT genetic analysis tool (Meyer, 2007).The 
model used in the analysis was, $\mathrm{y}_{\mathrm{ijk}}=\mathrm{Xb}_{\mathrm{j}}+\mathrm{Z}_{\mathrm{j}}+\mathrm{e}_{\mathrm{ijk}}$, Where, $\mathrm{y}_{\mathrm{ijk}}$ is the vector of observations, $\mathrm{X}$ is the incidence matrix for fixed effects with dimension ( $\mathrm{n} \times \mathrm{p}$ ), $\mathrm{Z}$ is the incidence matrix for random sire effect with dimension ( $\mathrm{n} \times \mathrm{q}), \mathrm{b}_{\mathrm{i}}$ is the vector of fixed effects with dimension ( $\mathrm{p} \times 1), \mathrm{S}_{\mathrm{j}}$ is the vector of sire effect with dimension (q x 1) and $\mathrm{e}_{\mathrm{ij \textrm {k }}}=$ vector of random residual effects with dimension ( $\mathrm{n} \times 1)$ with mean zero and variance $\left(0, \sigma \mathrm{e}^{2}\right)$. It was assumed that the expectations $(\mathrm{E})$ of the variables are, $\mathrm{E}(\mathrm{y})=\mathrm{Xb}$; $\mathrm{E}(\mathrm{s})=\mathrm{E}(\mathrm{e})=0 ; \operatorname{Var}(\mathrm{s})=\mathrm{A} \sigma \mathrm{s}^{2} ; \operatorname{Var}(\mathrm{e})={\mathrm{I} \sigma \mathrm{e}^{2}}^{2}$ and $\operatorname{Var}(\mathrm{y})=\mathrm{ZAZ} \mathbf{Z}^{\prime} \sigma^{2} \mathrm{~s}$ $+\mathrm{R}$.

From the above the mixed model equation developed as follows

$$
\left[\begin{array}{rr}
X^{\prime} X & X^{\prime} z \\
z^{\prime} X & z^{\prime} Z+A^{-1} \alpha
\end{array}\right]\left[\begin{array}{l}
\hat{b} \\
\hat{a}
\end{array}\right]=\left[\begin{array}{l}
x^{\prime} y \\
z_{y}^{\prime}
\end{array}\right]
$$

Where, $\alpha=\frac{\sigma^{2} \varepsilon}{\sigma_{s}^{2}}=\frac{\left(4-h^{2}-\right.}{h^{2}}$, and $\mathrm{A}$ is the numerator relationship matrix (NRM) of all the animals, which has nonzero off-diagonals only for the animal's parents, progeny, and mates. The elements of A can contain additive genetic effects, nonadditive genetic effects, maternal effects, and permanent environmental effects.

In BLUP-AM, the single trait animal model was considered for estimation of breeding values using WOMBAT software (Meyer, 2007) as, $\mathrm{Y}_{\mathrm{ijk}}=\mathrm{Xb}_{\mathrm{i}}+\mathrm{Z}_{\mathrm{a}_{\mathrm{j}}}+\mathrm{e}_{\mathrm{ijk}}$, Where, $\mathrm{Y}_{\mathrm{ijk}}$ is vector of observations, $b_{i}$ is vector of observation of fixed effects, $a_{j}$ is vector of additive genetic effect (Random animal effect), $X$ is design matrix/Incidence matrix of fixed effect, $\mathrm{Z}$ is design matrix/ Incidence matrix of random effect and $\mathrm{e}_{\mathrm{ijk}}$ is vector of residual errors with $\mathrm{E}(\mathrm{y})=\mathrm{Xb}$. Further, $\mathrm{E}(\mathrm{s})=\mathrm{E}(\mathrm{e})=0$; $\operatorname{Var}(\mathrm{a})=\mathrm{A} \sigma_{\mathrm{a}}^{2}$; $\operatorname{Var}(\mathrm{e})=\mathrm{I \sigma}_{\mathrm{e}}^{2}=\mathrm{R}$, and $\operatorname{Cov}(\mathrm{a}, \mathrm{e})=0$, so that $\operatorname{Var}(\mathrm{y})=\mathrm{ZGZ}+\mathrm{R}, \mathrm{A}$ is a numerator relationship matrix.

From above the Mixed Model Equation (MME) obtained was,

$$
\left[\begin{array}{rr}
x^{\prime} x & x^{\prime} z \\
z^{\prime} X & Z^{\prime} z+A^{-1} a
\end{array}\right]\left[\begin{array}{l}
\hat{b} \\
\hat{a}
\end{array}\right]=\left[\begin{array}{l}
x^{\prime} y \\
z^{\prime} y
\end{array}\right]
$$

Where, $\alpha=\sigma^{2}{ }_{e} / \sigma^{2}$; imilar to sire model but $\sigma^{2}{ }_{a}=\sigma^{2}{ }_{s} / 0.25$

\section{Effectiveness of various sire evaluation methods}

The sires were ranked as per their breeding values for AFC in each heat stress zone under study. The effectiveness of different sire evaluation methods were judged by using five criteria viz., within sire variance or error variance, AIC, BIC, Coefficient of Determination $\left(\mathrm{R}^{2}\right)$ and Spearman's rank correlation coefficients. The rank correlations between the rankings of sires based on their breeding values, estimated by different models was tested by Spearman's rank correlation method. Higher rank correlation between the sire evaluation methods indicated higher degree of similarity of ranking by two methods.

\section{Results and Discussion}

Milk production can be economized efficiently if we reduce the $\mathrm{AFC}$ of an animal as it reduces the generation interval and thereby increases genetic gain. It further increases the productive life of an animal and ultimately improves the profitability of dairy enterprise. The overall least-squares mean for $\mathrm{AFC}$ in the present study was estimated to be $1419.61 \pm 2.18$ days. The estimated means were significantly $(p<0.01)$ influenced by the effect of cluster and period of birth. The estimate obtained was in agreement with those obtained by Chaudhari (2016), Prajapati et al. (2017), Sathwara et al. (2018), and Parmar et al. (2019). The significant effect of period and cluster of birth of animals indicates variation in farm management practices over the period and geographical locations.

$\mathrm{AFC}$ in the present study was estimated to have moderately low heritability by LSML and BLUP-AM whereas high by BLUP$\mathrm{SM}$, which were significantly different from zero ( $\mathrm{P} \mathrm{d}$ " 0.01$)$. It was estimated to be $0.13 \pm 0.02$, by paternal half-sib method; 0.14 \pm 0.02 by BLUP-AM and $0.775 \pm 0.02$ by BLUP-SM. The present finding of LSML and BLUP-AM were in accordance with those reported by Chaudhari (2016), Sathwara (2018), Parmar et al. (2019) and Bhatt (2019). Further improvement in AFC in this population of Mehsana buffalo may be effective even by individual or pedigree selection.

\section{Quantification of effect of heat stress}

The average monthly AFC based on the month of birth is being presented against THI values for the corresponding month (Fig. 2). The result of linear regression to assess the suitability of THI model and to quantify change in age at first calving with per unit change in THI value are presented in Table 3.

It can be observed that the decrease in AFC with per unit increase in THI ranged from 0.82 to 1.27 days, depending on the THI models used. Based on the model evaluation criteria, model 6 was found to be the best suited and model 4 as the least suited model (Table 3). Result obtained very well depicts that there was very less impact of heat stress on AFC. This may be reasoned due to the fact that the duration between the births to calving encompasses all the seasons and the seasons are being repeated many times. The month-wise averages for AFC during the twentyfour years along with the monthly average THI values with all nine models are presented in Table 4 and Figure 1.

The lowest average AFC in Mehsana buffalo was observed to be 1349.24 days in the month of May, where corresponding average THI was 82.37. Similarly, the highest AFC was 1403.93 days in 
Fig.1 Monthly averages of THI values estimated by various THI models

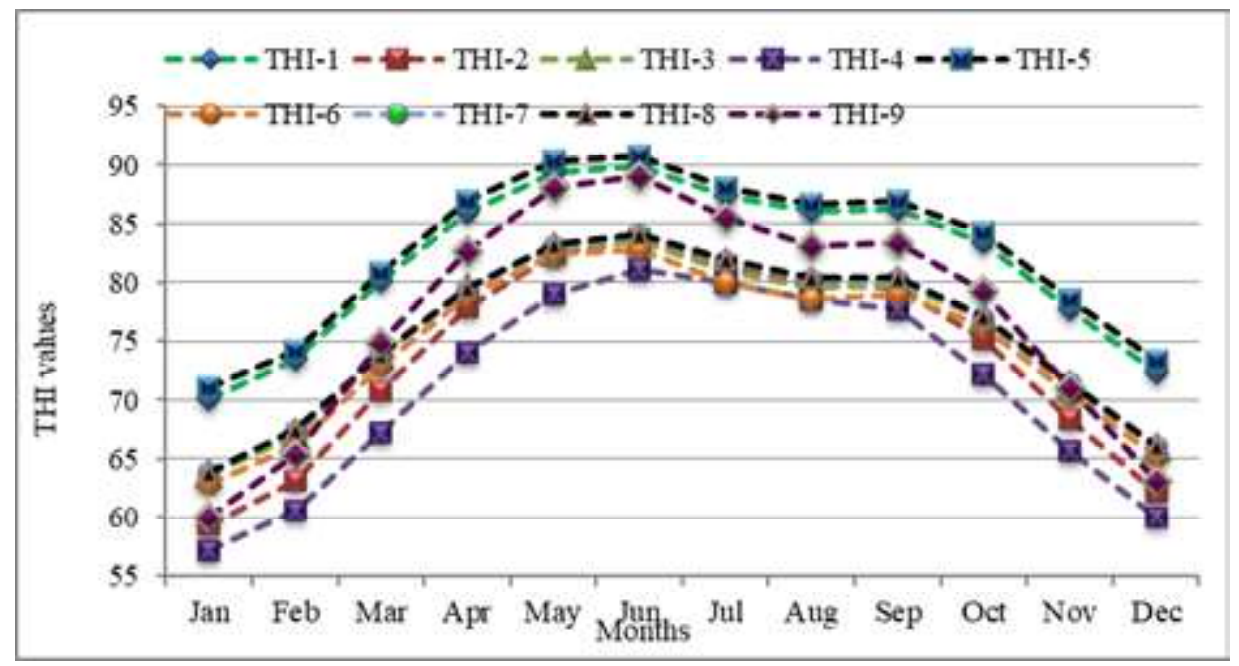

Table 1 Various heat stress models utilised for calculation of average monthly THI

\begin{tabular}{llc}
\hline Heat stress models & Formulae & References \\
\hline THI1 & {$\left[0.4 \times\left(\mathrm{T}_{\mathrm{db}}+\mathrm{T}_{\mathrm{wb}}\right)\right] \times 1.8+32+15$} & (Thom, 1959) \\
THI2 & $\left(0.35 \times \mathrm{T}_{\mathrm{db}}+0.65 \times \mathrm{T}_{\mathrm{wb}}\right) \times 1.8+32$ & (Bianca, 1962) \\
THI3 & $\left(\mathrm{T}_{\mathrm{db}}+\mathrm{T}_{\mathrm{wb}}\right) \times 0.72+40.6$ & (NRC, 1971) \\
THI4 & $\left(0.15 \times \mathrm{T}_{\mathrm{db}}+0.85 \times \mathrm{T}_{\mathrm{wb}}\right) \times 1.8+32$ & (Bianca, 1962) \\
THI5 & $\left(0.55 \times \mathrm{T}_{\mathrm{db}}+0.2 \times \mathrm{T}_{\mathrm{dp}}\right) \times 1.8+32+17.5$ & (NRC, 1971) \\
THI6 & $\mathrm{T}_{\mathrm{db}}+\left(0.36 \times \mathrm{T}_{\mathrm{dp}}\right)+41.2$ & (Yousef, 1985) \\
THI7 & $\left(0.8 \times \mathrm{T}_{\mathrm{db}}\right)+\left[(\mathrm{RH} / 100) \times\left(\mathrm{T}_{\mathrm{db}}-14.4\right)\right]+46.4$ & (Mader et al. 2006) \\
THI8 & $\left(1.8 \times \mathrm{T}_{\mathrm{db}}+32\right)-\left(0.55-0.0055 \times \mathrm{RH} \times\left(1.8 \times \mathrm{T}_{\mathrm{db}}-26\right)\right.$ & $(\mathrm{NRC,} \mathrm{1971)}$ \\
THI9 & $3.43+1.058 \times \mathrm{T}_{\mathrm{db}}-0.293 \times \mathrm{RH}+0.0164 \times \mathrm{T}_{\mathrm{db}} \times \mathrm{RH}+35.7$ & $($ Berman et al. 2016) \\
\hline
\end{tabular}

Table 2 Average monthly THI estimated under various THI models

\begin{tabular}{llllllllll}
\hline THI models & THI-1 & THI-2 & THI-3 & THI-4 & THI-5 & THI-6 & THI-7 & THI-8 & THI-9 \\
\hline January & 70.06 & 59.27 & 63.66 & 57.20 & 71.00 & 62.88 & 63.85 & 63.89 & 60.00 \\
February & 73.42 & 63.09 & 67.02 & 60.52 & 74.19 & 66.11 & 67.42 & 67.49 & 65.42 \\
March & 80.12 & 70.78 & 73.72 & 67.28 & 80.86 & 72.84 & 73.79 & 73.90 & 74.82 \\
April & 85.98 & 77.88 & 79.58 & 74.09 & 86.88 & 78.90 & 79.37 & 79.51 & 82.74 \\
May & 89.37 & 82.38 & 82.97 & 78.93 & 90.33 & 82.37 & 83.16 & 83.29 & 88.03 \\
June & 89.92 & 83.68 & 83.52 & 81.06 & 90.81 & 82.85 & 84.05 & 84.15 & 89.12 \\
July & 87.42 & 81.41 & 81.02 & 79.94 & 88.03 & 80.03 & 81.85 & 81.91 & 85.50 \\
August & 86.03 & 79.86 & 79.63 & 78.62 & 86.61 & 78.60 & 80.33 & 80.38 & 83.15 \\
September & 86.19 & 79.61 & 79.79 & 77.79 & 86.94 & 78.94 & 80.34 & 80.40 & 83.45 \\
October & 83.36 & 75.19 & 76.96 & 72.17 & 84.29 & 76.29 & 77.04 & 77.14 & 79.21 \\
November & 77.66 & 68.33 & 71.26 & 65.67 & 78.60 & 70.55 & 71.43 & 71.50 & 71.11 \\
December & 72.36 & 62.10 & 65.96 & 59.98 & 73.36 & 65.26 & 66.08 & 66.13 & 63.19 \\
Average & 81.82 & 73.63 & 75.42 & 71.10 & 82.66 & 74.63 & 75.73 & 75.81 & 77.14 \\
\hline
\end{tabular}

November month in which average THI was 70.55. The difference in $\mathrm{AFC}$ was about 55 days between the months with highest and lowest AFC. However, statistical significance of these findings could not be established.

It can be deduced from the present study that though the heat stress and AFC were negatively associated, the relationship was not significant. However, the regression analysis indicated that an increase in THI was affiliated with the decline in AFC. Based on the best suited THI model (model 6), the AFC reduced by 1.26 days with per unit increase in THI. Similar finding was reported in Japanese Black cows by Oikawa (2017), who reported the decrease in AFC by 3.431 days with per unit increases in THI. Further, Teke and Akdag (2012) in Jersey cows and Bahashwan (2020) in Dhofari cattle reported similar observation based on THI value as well as season, respectively on $\mathrm{AFC}$, however, instead of month of birth they took month of insemination as classifying criteria.

\section{The estimates of breeding value}


Fig.2 Month-wise Age at First Calving under best suited model

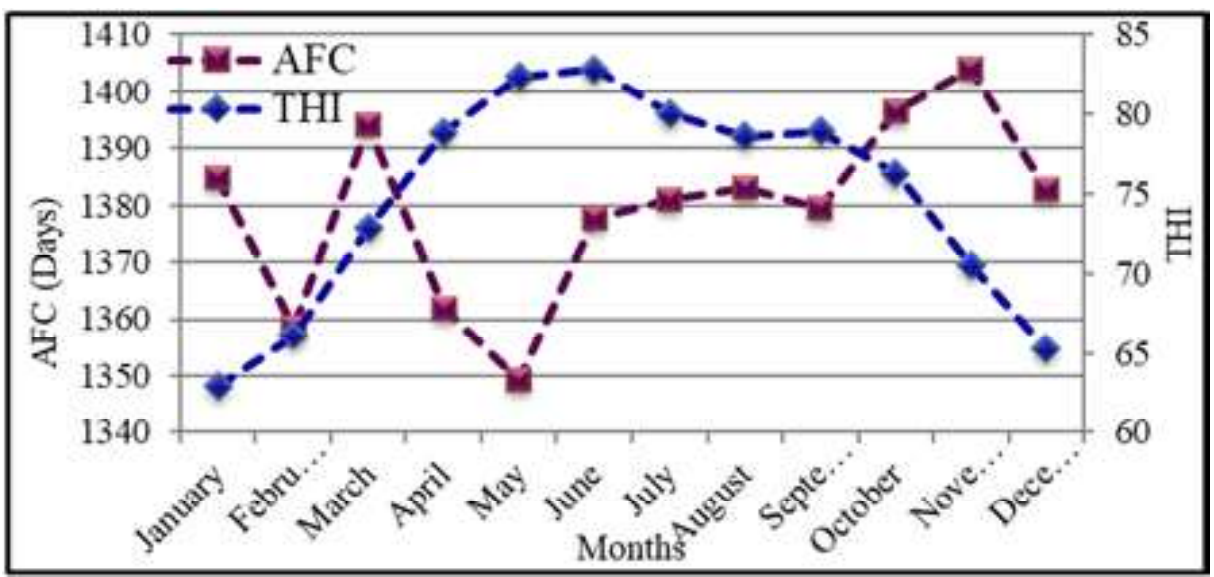

Table 3 Regression of AFC on THI under different THI models

\begin{tabular}{llllllll} 
THI & $\mathrm{b}$ & Intercept & Sig. & $\mathrm{R}^{2}$ & Ad. $\mathrm{R}^{2}$ & AIC & BIC \\
\hline THI-1 & -1.22 & 1481.13 & NS & 0.0065 & 0.0025 & 3048.413 & 3059.001 \\
THI-2 & -0.95 & 1451.26 & NS & 0.0061 & 0.0021 & 3048.507 & 3059.095 \\
THI-3 & -1.22 & 1473.31 & NS & 0.0057 & 0.0053 & 3048.413 & 3059.001 \\
THI-4 & -0.90 & 1445.25 & NS & 0.0055 & 0.0015 & 3048.654 & 3059.243 \\
THI-5 & -1.27 & 1486.04 & NS & 0.0069 & 0.00291 & 3048.304 & 3058.892 \\
THI-6 & -1.26 & 1475.22 & NS & 0.0069 & 0.00292 & 3048.303 & 3058.891 \\
THI-7 & -1.17 & 1469.55 & NS & 0.0061 & 0.00211 & 3048.509 & 3059.097 \\
THI-8 & -1.17 & 1469.62 & NS & 0.0061 & 0.00213 & 3048.503 & 3059.092 \\
THI-9 & -0.82 & 1444.50 & NS & 0.0061 & 0.00216 & 3048.496 & 3059.084 \\
\hline
\end{tabular}

Table 4 Month-wise average THI and AFC of all the animals calved in that month

\begin{tabular}{lllc}
\hline Months & THI value (THI-6) & AFC (days) & No. of animals \\
\hline January & 62.88 & 1384.98 & 327 \\
February & 66.11 & 1358.60 & 160 \\
March & 72.84 & 1394.06 & 101 \\
April & 78.90 & 1361.78 & 120 \\
May & 82.37 & 1349.24 & 243 \\
June & 82.85 & 1377.59 & 434 \\
July & 80.03 & 1380.94 & 850 \\
August & 78.60 & 1383.09 & 1150 \\
September & 78.94 & 1379.58 & 1394 \\
October & 76.29 & 1396.66 & 1362 \\
November & 70.55 & 1403.93 & 1034 \\
December & 65.26 & 1382.63 & 616 \\
\hline
\end{tabular}

The breeding value of the top ten sires along with average breeding value under different heat stress zones are presented in table 5. Average expected breeding values of age at first calving by BLUP-SM within different heat stress zones were estimated to be 1389.36 (Range - 269.19 days), 1380.37 (Range - 236.89 days) and 1375.04 days (Range - 412.56 days) for NHSZ, HSZ and CHSZ, respectively. Though heat stress zone-wise evaluation of Mehsana buffalo bulls for AFC has not been carried out till now, the estimated general breeding value for AFC in the present study was in accordance with Sathwara (2018). About 53.85\% of the sires in NHSZ, 50.35\% in HSZ and $48.95 \%$ in CHSZ were having higher breeding values than their respective averages. Similarly, the breeding value estimated by BLUP-AM for various zones was 1389.33 days in NHSZ, 1382.85 days in HSZ and 1375.53 days in CHSZ which was almost equal to those obtained by BLUP-SM.

The effectiveness of sire evaluation models (BLUP-AM and BLUP-SM) applied to AFC were compared on the basis of lower error variance, AIC and BIC as well as higher coefficient of determination $\left(\mathrm{R}^{2}\right)$ value and it was found that BLUP-AM was th

e best suitable model (Table 6) for sire evaluation based on all the criteria, except error variance. Estimated Spearman's rank correlation coefficient further substantiate this. 

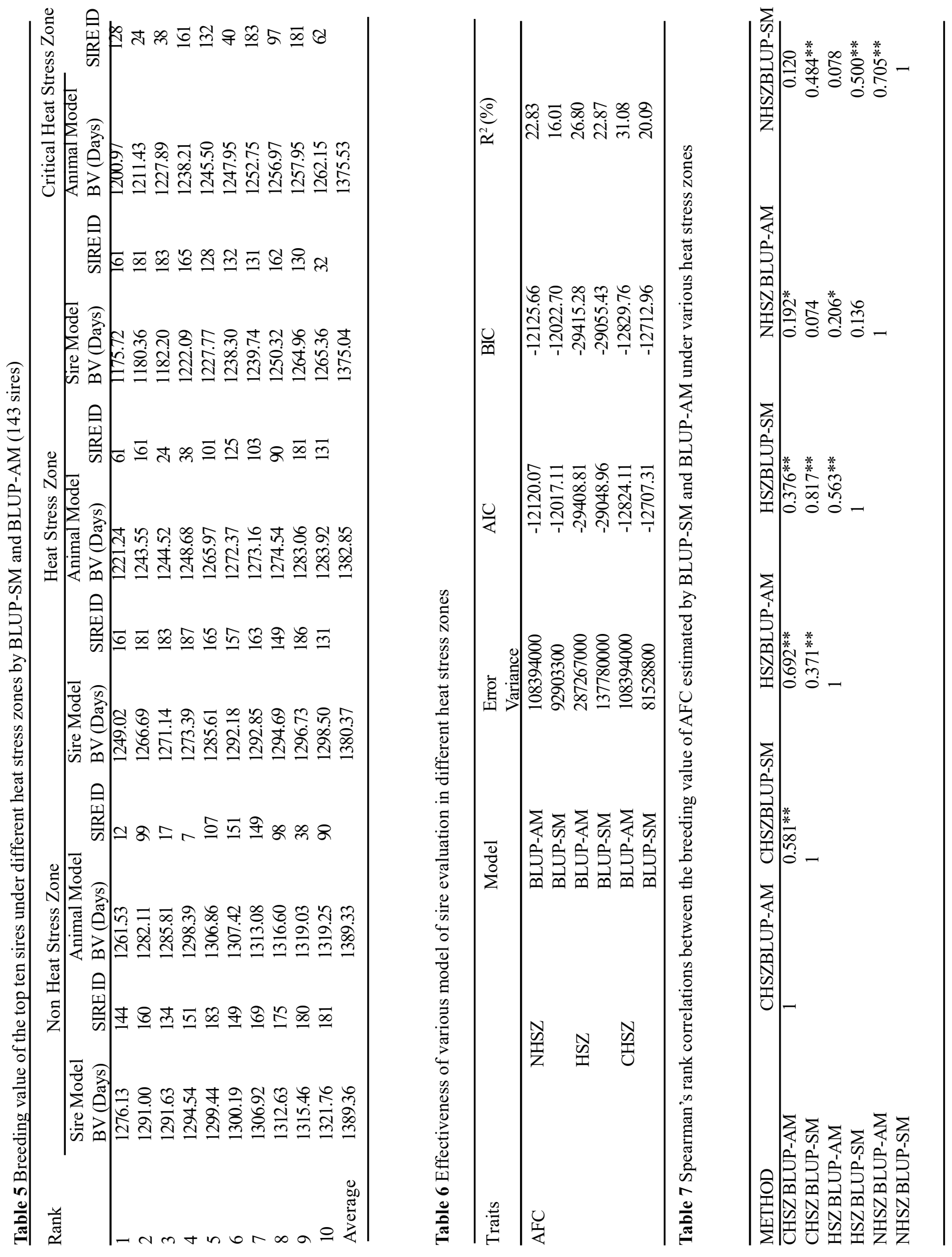
Correlations were also established between BLUP-SM and BLUPAM under all the three zones separately and it was observed that BLUP-SM under HSZ and CHSZ were recorded to have highest correlation. Similar high correlations were also recorded among BLUP-AM and BLUP-SM within a heat stress zone. However, correlation coefficients between the ranking of sires of NHSZ and CHSZ were found to be very low and significant (Table 7). Similar to the present findings Sathwara (2018) observed moderate to high correlation between the BLUP-SM and BLUPAM in his study in Mehsana buffaloes. No literature could be obtained which compare the rankings of sires between different zones of the year.

\section{Conclusions}

It may be concluded that THI model- 6 was found to be the bestsuited model for determining the impact of heat stress on age at first calving in arid and semi-arid region of North Gujarat which indicates that, area and trait-specific models, need to be identified. Age at first calving was declining by 1.26 days with per unit increase in THI, which was not reported to be statistically significant. The study further indicated that the bulls which gave superior performance in NHSZ may not be as superior for HSZ and CHSZ which revealed that heat stress may be an important factor to be considered while evaluating the sires.

\section{References}

Anonymous (2013) Breed wise estimated livestock population based on breed survey-2013, Ministry of Agriculture \& Farmer Welfare, Department of Animal Husbandry, Dairying \& Fisheries, Krishi Bhawan, New Delhi

Bahashwan S (2020) The Dhofari cattle breed; productive and reproductive performance. Development 32:2

BAHS (2019) Basic Animal Husbandry Statistics - 2019. Ministry of Fisheries, Animal Husbandry \& Dairyng, http://dadf.gov.in (Accessed on $26^{\text {th }}$ August, 2020)

Becker WA (1975) Manual of Quantitative Genetics, Washington State University, Pullman, Washington. pp.170

Berman A, Horovitz T, Kaim M, Gacitua H (2016) A comparison of THI indices leads to a sensible heat-based heat stress index for shaded cattle that aligns temperature and humidity stress. Int J Biometeorol 60:1453-62

Bhatt TM (2019) Genetic evaluation of Mehsana buffaloes based on various lactation curve models. M.V.Sc Thesis, Sardarkrushinagar Dantiwada Agricultural University, Sardarkrushinagar, Gujarat

Bianca W (1962) Relative importance of dry-and wet-bulb temperatures in causing heat stress in cattle. Nature 195:251-252

Chaudhari JD (2016) Genetic evaluation of Mehsana buffaloes under field progeny testing programme in Mehsana district. M.V.Sc. Thesis, Sardarkrushinagar Dantiwada Agricultural Univeresity, Sardarkrushinagar, Gujarat
Draper NR, Smith H (1998) Applied regression analysis. John Wiley \& Sons, Inc., New York Vol. 326

Harvey WR (1990) User's Guide for LSMLWM and MIXMDL PC-2 version. Mixed Model Least-Squares and Maximum Likelihood Computer Programme. 4255. Mumford Drive, Columbus, Ohio 43220, U.S.A pp. $10-41$

Henderson CR (1975) Best linear unbiased estimation and prediction under a selection model. Biometrics 31:423-47

Kramer CY (1957) Extension of multiple range tests to group correlated adjusted means. Biometrics 13:13-18

Mader TL, Davis MS, Brown-Brandl T (2006) Environmental factors influencing heat stress in feedlot cattle. J Anim Sci 84:712-719

Meyer K (2007) WOMBAT-A tool for mixed model analyses in quantitative genetics by restricted maximum likelihood (REML). J Zhejiang Univ Sci 8:815-821

National Research Council (1971) A guide to environmental research on animals. National academic science. Washington, DC

Oikawa T (2017) Effect of heat stress on age at first calving of Japanese Black cows in Okinawa. Anim Sci J 88:439-444

Ojango JM, Pollott GE (2001) Genetics of milk yield and fertility traits in Holstein-Friesian cattle on large-scale Kenyan farms. J Anim Sci 79:1742-1750

Parmar GA, Gupta JP, Chaudhari JD, Pandey DP, Prajapati BM, Sathwara RN, Patel PA (2019) Study of genetic and non genetic factors affecting age at first calving and wet average in Mehsana buffaloes. Buffalo Bull 38:11-17

Prajapati BM, Gupta JP, Pandey DP, Chaudhari JD, Parmar GA, PA P, Prajapati MN, Sathawara RN (2017) Non genetic factors affecting age at first calving in Mehsana buffaloes. Life Sciences Leaflets $87: 8-15$

Purohit PB, Gupta JP, Chaudhari JD, Bhatt TM, Pawar MM, Srivastava AK, Patel MP (2020) Effect of Heat Stress on Production and Reproduction Potential of Dairy Animals Vis-À-Vis Buffaloes. Int J Livest Res 10:1-23

$\mathrm{R}$ Core Team. (2019). R: A language and environment for statistical computing. R Foundation for Statistical Computing, Vienna, Austria. URL https://www.R-Project.org/

Sathwara RN (2018) Univariate versus bivariate models for genetic evaluation of Mehsana buffaloes using first lactation production and fertility traits. M.V.Sc. Thesis, Sardarkrushinagar Dantiwada Agricultural Univeresity, Sardarkrushinagar, Gujarat

Sathwara RN, Gupta JP, Chaudhari JD, Parmar GA, Prajapati BM, Bhatt TM, Patel MA (2018) Effect of non-genetic factors on various reproduction traits in Mehsana buffaloes. In: National symposium on Sustainable management of livestock and poultry diversity for enhancing the farmer's income. Bikaner, Rajasthan, India, 8-10 February, pp. 259

Swiger LA, Harvey WR, Everson DO, Gregory KE (1964) The variance of intraclass correlation involving groups with one observation. Biometrics 1:818-826

Teke B, Akdag F (2012) The effect of heat stress on some reproductive traits in Jersey cows under semi-humid conditions in Turkey. Bulg $\mathrm{J}$ Agric Sci 18:506-510

Thom EC (1959) The discomfort index. Weatherwise 12:57-61

Yousef MK (1985) Stress physiology in livestock. Volume I. Basic principles. CRC press 